\title{
Infarctus avec hypertonie vagale
}

\section{Myocardial infarction and vagal hypertonie}

\section{P. Taboulet}

Reçu le 14 décembre 2011 ; accepté le 28 décembre 2012

(C) SFMU et Springer-Verlag France 2012

Un patient de 86 ans est amené par les pompiers suite à un malaise avec sensation d'oppression thoracique, sueurs et vomissements.

L'ECG révèle en début de tracé des complexes QRS lents et larges avec retard droit (aspect RsR' en V1) non précédés par une onde $\mathrm{P}$ (Fig. 1). Ce rythme ventriculaire se ralentit de 54 à $51 / \mathrm{mn}$ et en fin de tracé apparaît une onde $\mathrm{P}$ sinusale à $56 / \mathrm{mn}$. Cette activité sinusale - jusque là cachée dans les
QRS - prend la commande et le rythme devient sinusal (capture sinusale). On observe également des anomalies du QRS-ST-T compatible avec un infarctus inférieur en cours d'évolution.

Cette observation rappelle l'importance des tracés longs devant tout trouble du rythme complexe et la fréquence de l'hypertonie vagale au cours d'un infarctus inférieur (secondaire à l'ischémie auriculaire droite).

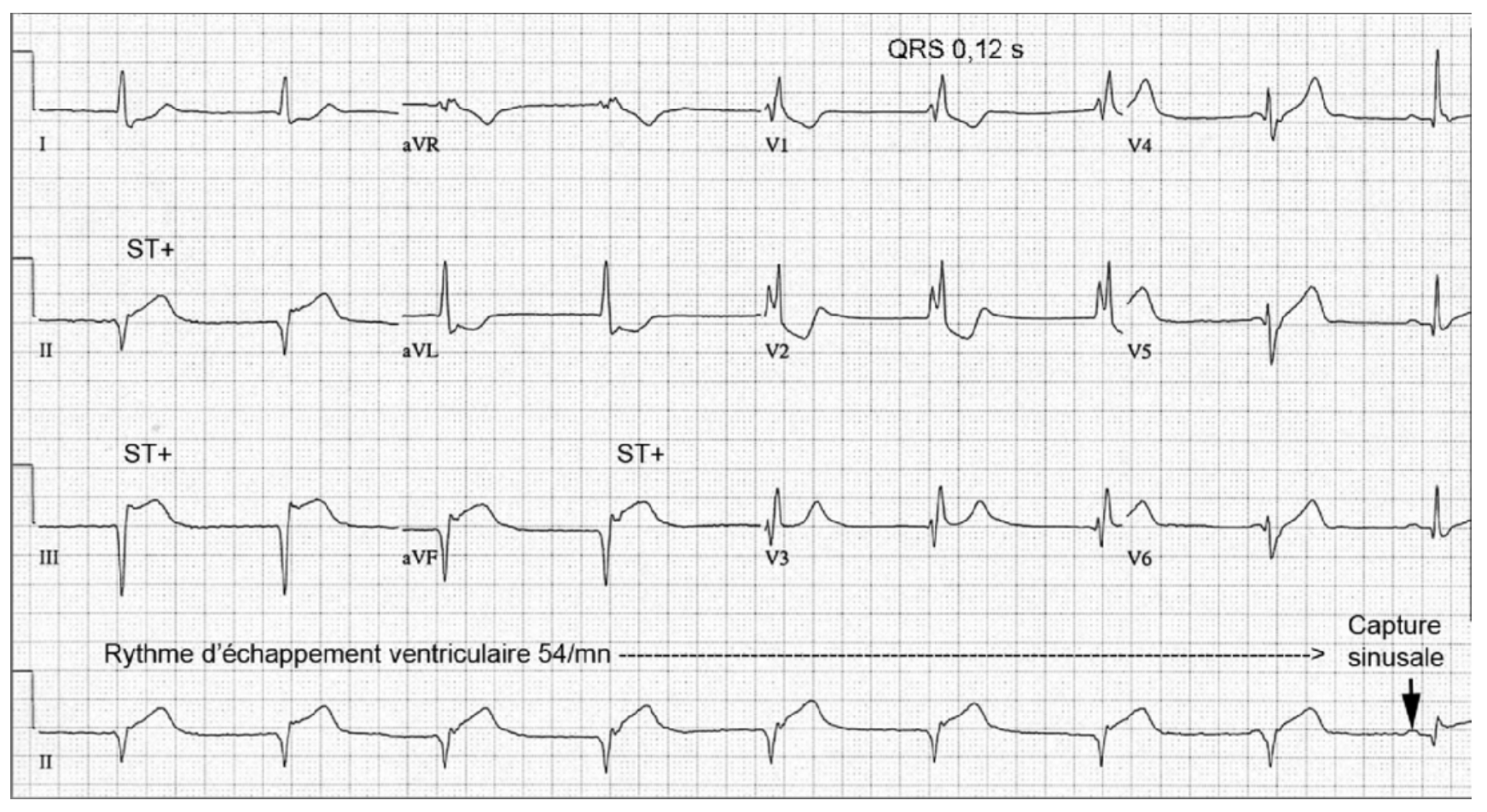

Fig. 1 ECG : complexes QRS lents et larges avec retard droit (aspect RsR' en V1) non précédés par une onde P

P. Taboulet $(\bowtie)$

Hopital Saint-Louis, Assistance Publique-Hôpitaux de Paris,

Service des Urgences, 1, avenue Claude Vellefaux,

75010, Paris, France

e-mail : pierre.taboulet@sls.aphp.fr 